\title{
Intractable hypercalcaemia during pregnancy and the postpartum secondary to pathogenic variants in CYP24A1
}

\author{
Nirusha Arnold1', Victor O'Toole', Tien Huynh1, Howard C Smith², Catherine Luxford3', \\ Roderick Clifton-Bligh ${ }^{3}$ and Creswell J Eastman ${ }^{1,2}$
}

'Westmead Private Hospital, Westmead, Sydney, New South Wales, Australia, 2Westmead Teaching Hospital, and ${ }^{3}$ Kolling Institute of Medical Research, Royal North Shore Teaching Hospital, The University of Sydney, Sydney, New South Wales, Australia
Correspondence should be addressed to C J Eastman Email creswell.eastman@sydney. edu.au

\section{Summary}

Parathyroid-independent hypercalcaemia of pregnancy, due to biallelic loss of function of the P450 enzyme CYP24A1, the principal inactivator of $1,25(\mathrm{OH})_{2} \mathrm{D}$ results in hypervitaminosis $\mathrm{D}$, hypercalcaemia and hypercalciuria. We report two cases of this disorder, with intractable hypercalcaemia, one occurring during gestation and into the postpartum, and the other in the postpartum period. Case 1, a 47-year-old woman with a twin pregnancy conceived by embryo transfer, presented with hypercalcaemia at 23 weeks gestation with subnormal serum parathyroid hormone (PTH) and normal serum $25-\mathrm{OH}$ $\mathrm{D}$ levels. She was admitted to hospital at 31 weeks gestation with pregnancy-induced hypertension, gestational diabetes and increasing hypercalcaemia. Caesarean section at 34 weeks gestation delivered two healthy females weighing 2.13 $\mathrm{kg}$ and $2.51 \mathrm{~kg}$. At delivery, the patient's serum calcium level was $2.90 \mathrm{mmol} / \mathrm{L}$. Postpartum severe hypercalcaemia was treated successfully with Denosumab $60 \mathrm{mg} \mathrm{SCl}$, given on two occasions. CYP24A1 testing revealed she was compound heterozygous for pathogenic variants c.427_429delGAA, (p.Glu143del) and c.1186C>T, (p.Arg396Trp). Case 2, a 36-year-old woman presented 4 days after the delivery of healthy twins with dyspnoea, bradycardia, severe headaches, hypertension and generalized tonic-clonic seizures after an uneventful pregnancy. She was hypercalcaemic with a suppressed PTH, normal $25(\mathrm{OH}) \mathrm{D}$, and elevated $1,25(\mathrm{OH})_{2} \mathrm{D}$ levels. Her symptoms partially responded to i.v. saline and corticosteroids in the short term but bisphosphonates such as Pamidronate and Zoledronic acid did not result in sustained improvement. Denosumab $120 \mathrm{mg} \mathrm{SCl}$ successfully treated the hypercalcaemia which resolved completely 2 months post-partum. CYP24A1 testing revealed she was homozygous for the pathogenic variant c.427_429delGAA, (p.Glu143del).

\section{Learning points:}

- Hypercalcaemia in pregnancy can be associated with considerable morbidity with few options available for management.

- In non-PTH-related hypercalcaemia the diagnosis of CYP24A1 deficiency should be considered.

- Making a definitive diagnosis of CYP24A1 deficiency by genetic testing delays the diagnosis, while the availability of serum 24,25 -dihydroxyvitamin $\mathrm{D}\left(24,25(\mathrm{OH})_{2} \mathrm{D}\right)$ will expedite a diagnosis.

- In pregnant women with CYP24A1 deficiency hypercalcaemia can worsen in the post-partum period and is more likely to occur with twin pregnancies but generally resolves within 2-3 months.

- Therapeutic alternatives are limited in pregnancy and their effectiveness is short-lived and mostly ineffective. Denosumab used in both our patients after delivery was the most effective agent normalizing calcium and may have benefit as a long-term therapeutic agent in preventing complications in patients with CYP24A1 deficiency. 


\section{Background}

Hypercalcaemia presenting initially during pregnancy or the postpartum period is a rare problem creating major challenges in diagnosis and management and may be responsible for a high rate of maternal and foetal complications $(1,2)$. It is usually PTH dependent with the commonest cause being a parathyroid adenoma. Rarely, it is PTH independent and may be due to a variety of rare conditions such as milk-alkali syndrome, granulomatous diseases, drugs, malignancy or benign parathyroid hormone-related peptide (PTHrP) secreting tumours (1). However, CYP24A1 mutations have recently been recognised as a cause of intractable hypercalcaemia in pregnancy $(1,2)$. Variants in CYP24A1 were first described in the 1950s when milk products in the United Kingdom were fortified with Vitamin D to prevent rickets, but caused an increase in the incidence of idiopathic infantile hypercalcaemia. In 2011, Schlingmann et al. described biallelic pathogenic variants in CYP24A1 as a likely cause of hypercalcaemia in these infants (3). The P450 enzyme CYP24A1 encodes Vitamin D 24-hydroxylase

\section{Normal Vitamin D Physiology}

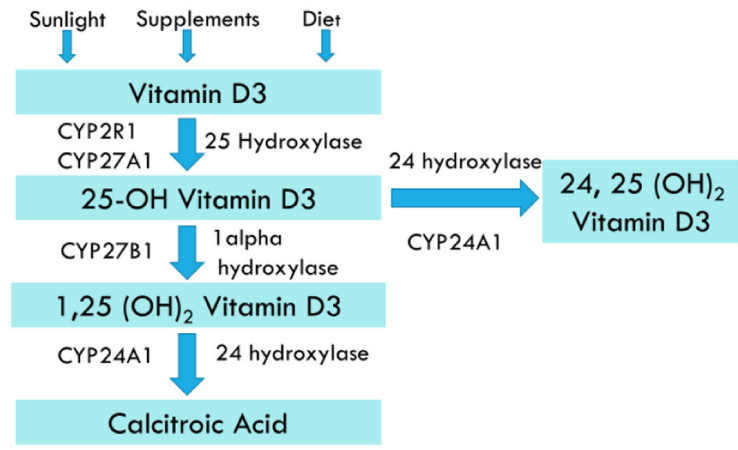

Vitamin D Physiology with CYP24A1 Deficiency

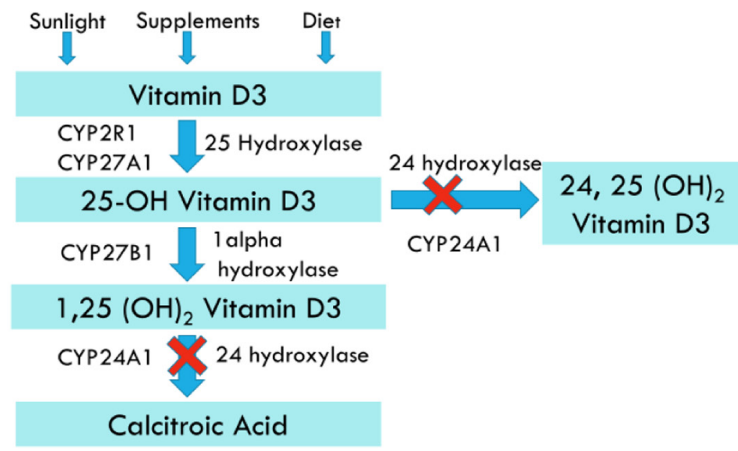

Figure 1

Pathways for metabolism of Vitamin D. which metabolises $1,25(\mathrm{OH})_{2} \mathrm{D}$ and $25(\mathrm{OH}) \mathrm{D}$ to inactive metabolites calcitroic acid and $24,25(\mathrm{OH})_{2} \mathrm{D}$ (Fig. 1). Patients with CYP24A1 deficiency are not able to convert this activated Vitamin D to the inactive metabolite $24,25(\mathrm{OH})_{2} \mathrm{D}$ resulting in hypercalcaemia with low PTH levels, normal to high $25(\mathrm{OH}) \mathrm{D}$ and $1,25(\mathrm{OH})_{2} \mathrm{D}$ levels, and hypercalciuria. Here we present two patients with CYP24A1 mutations, who came to attention for the first time in pregnancy and the postpartum period, demonstrating patterns in their clinical course, difficulties in diagnosis and finally a novel treatment strategy for this new entity.

\section{Case presentations}

\section{Case 1}

A 47-year-old woman conceived for the first time by embryo transfer. At 16-weeks gestation, with a twin pregnancy, she was noted to be iodine deficient with borderline subclinical hypothyroidism (serum TSH level $3.41 \mathrm{mIU} / \mathrm{L}$ with normal free T4 level and negative thyroid autoantibodies) and was commenced on levothyroxine 50 $\mu \mathrm{g}$ daily when she came to our clinic at 23-weeks gestation. She gave a history of recurrent calcium oxalate renal calculi, at ages 30,37 , and 43 years. There was a family history of type 2 diabetes and unconfirmed renal calculi.

At 23-week gestation her serum calcium was mildly elevated at $2.68 \mathrm{mmol} / \mathrm{L}$ (reference range: 2.15-2.55 $\mathrm{mmol} / \mathrm{L}$ ) and serum phosphate was $1.06 \mathrm{mmol} / \mathrm{L}$ (reference range: $0.8-1.5 \mathrm{mmol} / \mathrm{L}$ ). Parathyroid hormone (PTH) was subnormal at $1.0 \mathrm{pmol} / \mathrm{L}$ (reference range: 1.6-6.9 pmol/L), 25-hydroxyvitamin D $(25(\mathrm{OH}) \mathrm{D})$ was $103 \mathrm{nmol} / \mathrm{L}$ and $92 \mathrm{nmol} / \mathrm{L}$ on another occasion (reference range: 50-140 nmol/L). Her vitamin D 1000 IU daily, which she had been taking for 4 years, was stopped but she continued supplementary cholecalciferol via her prenatal vitamins. She had not been taking a calcium supplement and her diet was free of dairy products. A 75 g glucose tolerance test showed gestational diabetes mellitus.

She was admitted to hospital at 31-weeks gestation with pregnancy-induced hypertension complicated by gestational diabetes and increasing hypercalcaemia. Her BP was 140/90 associated with peripheral oedema and albuminuria.

Investigations

Serum calcium was $3.11 \mathrm{mmol} / \mathrm{L}$ and serum PTH remained undetectable. As the suppressed serum PTH level effectively excluded primary hyperparathyroidism, other diagnoses 
such as milk-alkali syndrome, underlying malignancy or granulomatous disease were excluded. Investigations revealed an elevated serum 1,25-dihydroxyvitamin D $\left(1,25(\mathrm{OH})_{2} \mathrm{D}\right)$ of $247 \mathrm{pmol} / \mathrm{L}$ (reference range: 60-208 $\mathrm{pmol} / \mathrm{L}$ ) and undetectable serum PTHrP raising the possibility of hypervitaminosis $\mathrm{D}$ as the cause of her hypercalcaemia. Serum 24,25-dihydroxyvitamin D $\left(24,25(\mathrm{OH})_{2} \mathrm{D}\right)$ measurement was not available. Imaging confirmed bilateral parenchymal calcification and a left ureteric calculus.

\section{Treatment}

The hypertension was treated with labetalol and methyldopa. Hypercalcaemia was partly controlled by i.v. fluids, furosemide $40 \mathrm{mg}$ daily and prednisone therapy $20 \mathrm{mg}$ daily, causing the patient to suffer intermittently from fluid overload and peripheral oedema. At no stage was it possible to maintain the serum calcium within the normal reference range. The introduction of prednisone required insulin therapy to control hyperglycaemia. Many different therapies to decrease the hypercalcaemia were considered, including parenteral bisphosphonates, calcitonin and denosumab, but in the absence of any safety data for these drugs during pregnancy, and in concern for f-etal welfare, none were administered.

Intensive f-etal surveillance was performed until caesarean section was performed at 34-weeks gestation with delivery of two healthy females weighing $2.13 \mathrm{~kg}$ and $2.51 \mathrm{~kg}$. At the time of delivery, the patient's serum calcium level was $2.90 \mathrm{mmol} / \mathrm{L}$. Neonatal hypocalcaemia did not occur. Both babies have developed normally without any signs of adverse effects. Monitoring of serum calcium postpartum showed persistently elevated levels in excess of $3.0 \mathrm{mmol} / \mathrm{L}$. Despite hydration with i.v. fluids and the use of furosemide and prednisone the serum calcium level rose to $3.52 \mathrm{mmol} / \mathrm{L} 2$ weeks after delivery. Breastfeeding was not established. She was treated with denosumab $60 \mathrm{mg}$ subcutaneously on two occasions 1 week apart. Her serum calcium level declined to $2.67 \mathrm{mmol} / \mathrm{L}$ within 4 days and then normalised on follow-up.

\section{Outcome and follow-up}

Genetic testing of the CYP24A1 (vitamin D 24-hydroxylase) gene revealed the patient to be compound heterozygous for pathogenic variants c.427_429delGAA, (p.Glu143del) and c.1186C $>$ T, (p.Arg396Trp). Both mutations have been reported as causing idiopathic hypercalcaemia of infancy (3).

\section{Case 2 presentation}

A 36-year-old woman presented 4 days after delivery of healthy twins with dyspnoea and bradycardia. Seven days after delivery her clinical condition rapidly deteriorated with severe headaches, hypertension and generalized tonic-clonic seizures. She complained of having experienced increasing lethargy, thirst and dyspnoea in the third trimester persisting after delivery. She had taken a prenatal vitamin supplement containing cholecalciferol $500 \mathrm{IU}$ and calcium during the pregnancy

She had two healthy children aged 10 and 9 years and suffered no complications during these singleton pregnancies or the post-partum period where she did not take any pre-natal vitamins. There was no history of renal calculi and no family history of hypercalcaemia, renal calculi or endocrine tumours.

\section{Investigations}

Investigations revealed grossly elevated serum calcium of $3.74 \mathrm{mmol} / \mathrm{L}$. A 24 -h urinary calcium was elevated at $14 \mathrm{mmol} /$ day (reference range: $2.5-7.5 \mathrm{mmol} /$ day). Serum PTH and PTHrP were both undetectable, and $25(\mathrm{OH})$ D level was $91 \mathrm{nmol} / \mathrm{L}$ and $1,25(\mathrm{OH})_{2} \mathrm{D}$ was $348 \mathrm{pmol} / \mathrm{L}$ (reference range: $60-208 \mathrm{pmol} / \mathrm{L}$ ) raising the possibility of hypervitaminosis D. Measurement of serum $24,25(\mathrm{OH})_{2} \mathrm{D}$ was not available. Other causes of hypercalcaemia were excluded through extensive investigations.

\section{Treatment}

Initial treatment was i.v. saline, i.v. hydrocortisone and pamidronate $(90 \mathrm{mg}$ ). Due to the seizures and hypertension she was also treated for eclampsia with labetalol, hydralazine and IV magnesium. Her serum calcium responded and decreased to $2.64 \mathrm{mmol} / \mathrm{L}$ in 2 days. However, once i.v. fluids were ceased, and the prednisone dose reduced, her calcium rose again despite maintaining a generous oral fluid intake. Her blood pressure rose, her headaches returned, and in 5 days her calcium had risen to $3.05 \mathrm{mmol} / \mathrm{L}$.

She was treated again with i.v. normal saline, oral prednisone, and this time i.v. zoledronic acid. Again, her calcium responded promptly and was $2.66 \mathrm{mmol} / \mathrm{L}$ after 2 days. Six days after administration of zoledronic acid her serum calcium had risen again to $2.92 \mathrm{mmol} / \mathrm{L}$ so a decision was made to intensify her treatment with glucocorticoid to dexamethasone. Her calcium decreased to $2.63 \mathrm{mmol} / \mathrm{L}$ a day later. Her calcium remained below $2.8 \mathrm{mmol} / \mathrm{L}$ for a further 7 days before starting to rise again. 


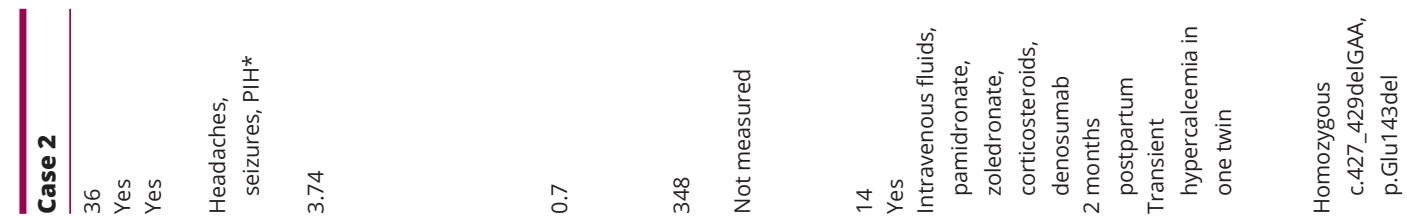
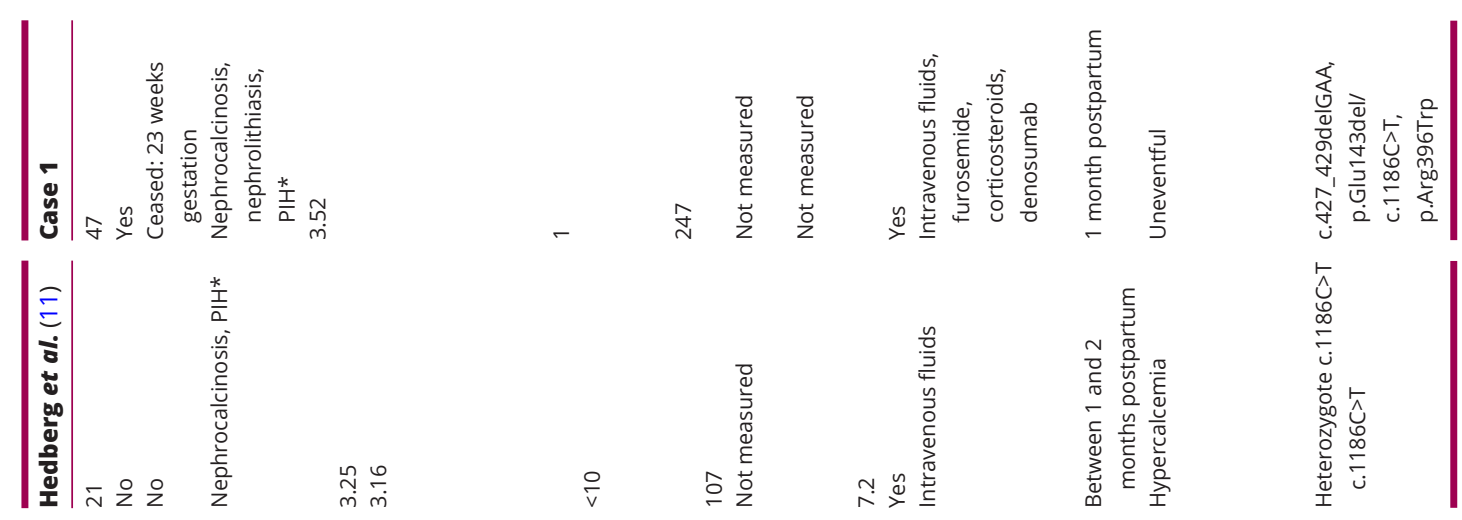

$\stackrel{\sim}{\sim} \underset{m}{\stackrel{0}{m}}$
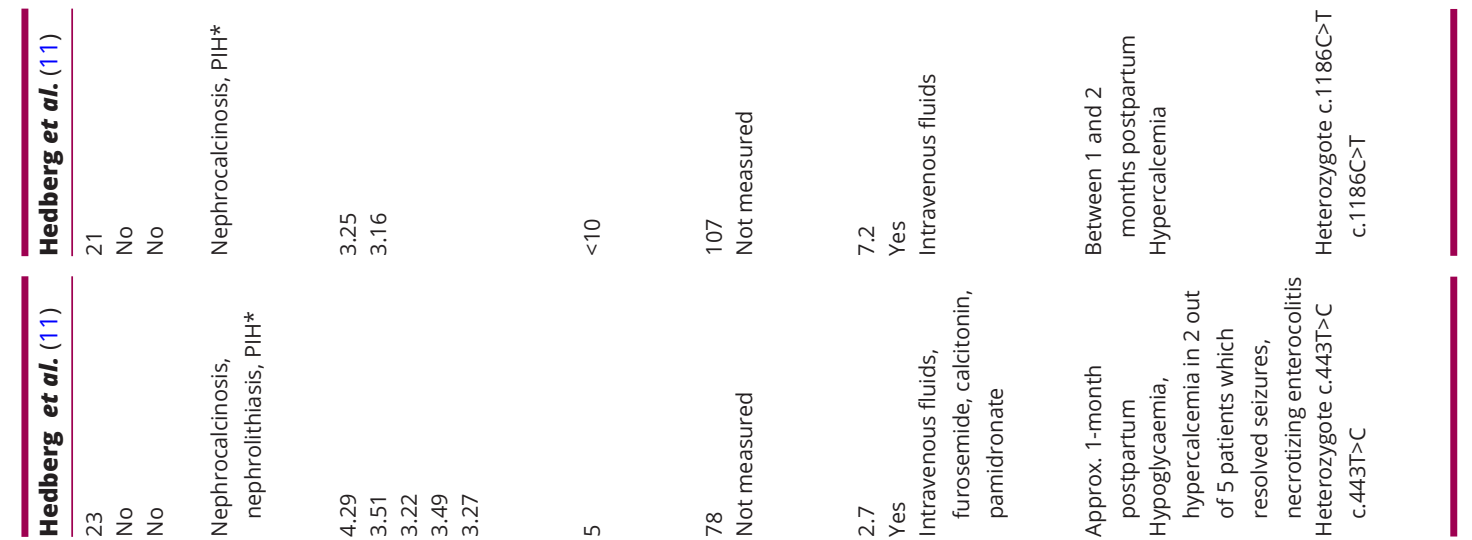

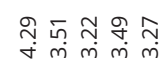
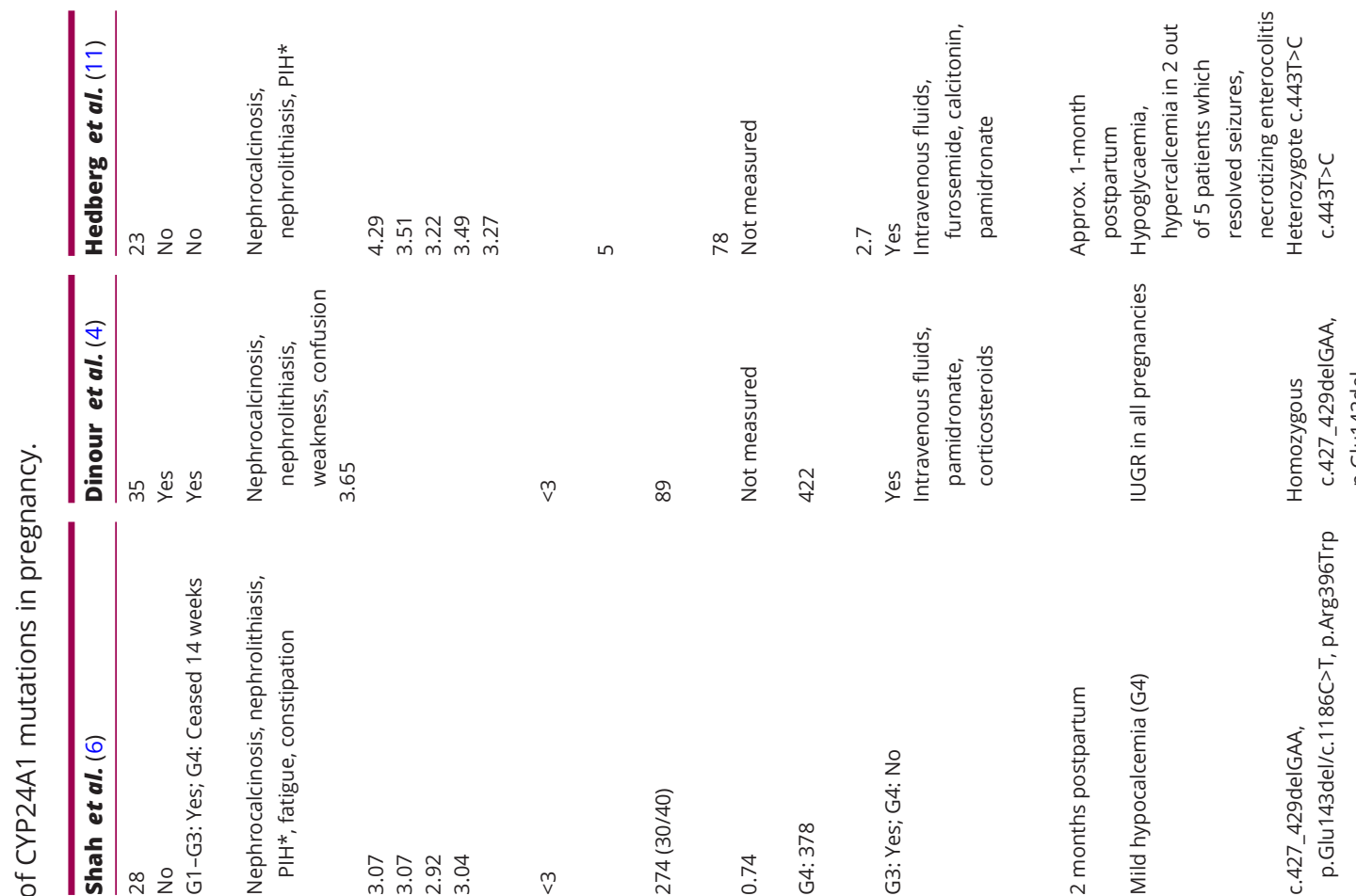

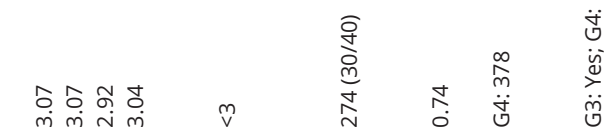
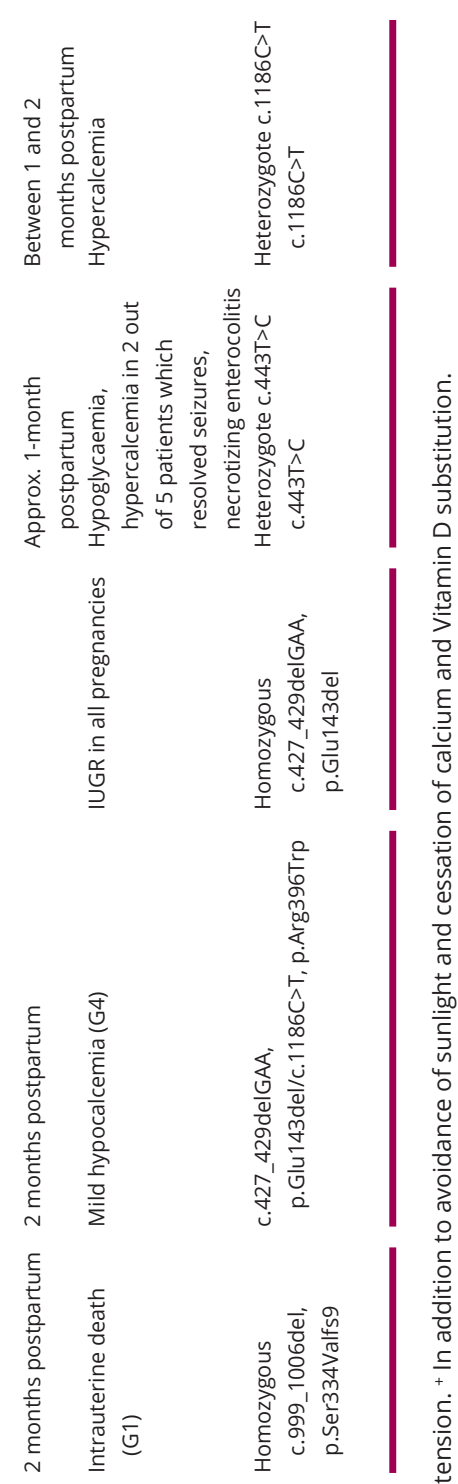

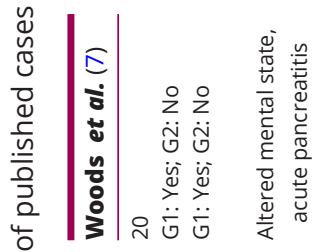

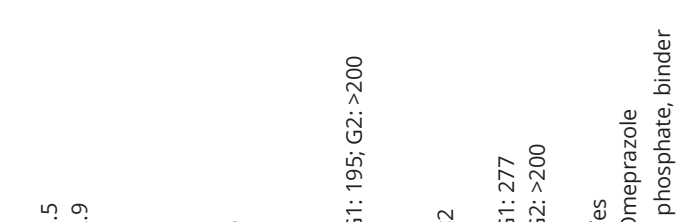

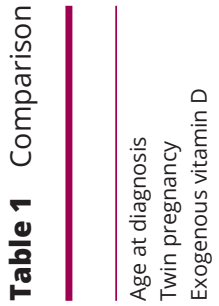
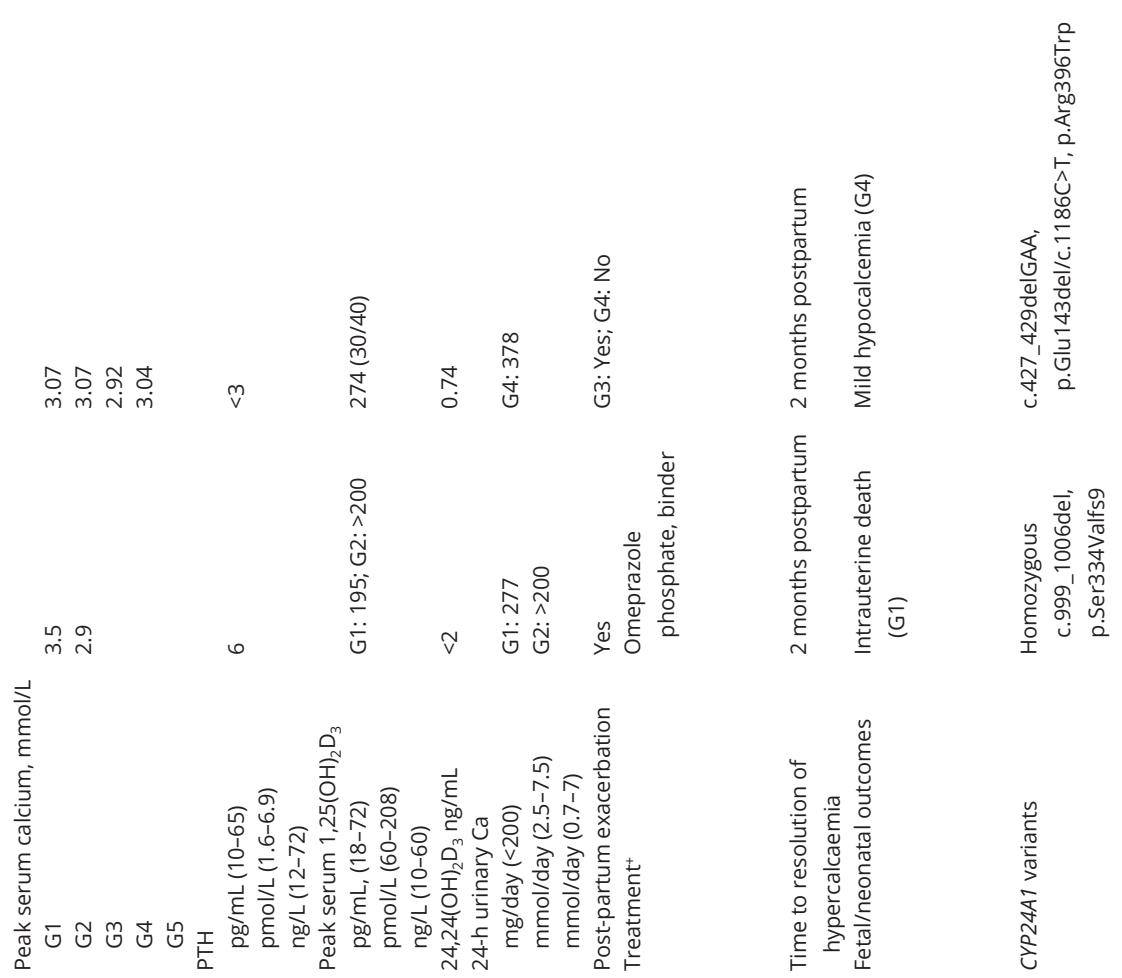
She was re-admitted, now 5 weeks post-partum, with a calcium of $3.06 \mathrm{mmol} / \mathrm{L}$. Serum $1,25(\mathrm{OH})_{2} \mathrm{D}$ was normal at $170 \mathrm{nmol} / \mathrm{L}$. She was treated again with i.v. normal saline, dexamethasone was continued, and this time denosumab $120 \mathrm{mg}$ was administered subcutaneously. Following these measures her serum calcium reduced to $2.61 \mathrm{mmol} / \mathrm{L}$ and normalized over 3 weeks. She has remained well and has required no further treatment.

\section{Outcome and follow-up}

Genetic testing of the CYP24A1 gene showed that she was homozygous for the pathogenic variant c.427_429delGAA, (p.Glu143del) (3).

\section{Discussion}

Diagnosis of CYP24A1 bi-allelic mutations in both patients was suspected but not confirmed by molecular testing until the postpartum. The lack of availability of an assay to measure $24,25(\mathrm{OH})_{2} \mathrm{D}$ delayed the causal diagnosis until after their recovery. A recent review (1) emphasises that in patients with pathogenic CYP24A1 variants, the serum $24,25(\mathrm{OH})_{2} \mathrm{D}$ is low because of reduced 24-hydroxylase activity, despite the presence of adequate amounts of substrate. Consequently, the ratio of $25(\mathrm{OH})$ D to $24,25(\mathrm{OH})_{2} \mathrm{D}$ measured on a simultaneous sample is elevated and is a better assessment of 24-hydroxylase activity (1) than the more variable $1,25(\mathrm{OH})_{2} \mathrm{D}$ levels (4).

Our cases demonstrated the severe morbidity and potential mortality due to the expression of CYP24A1 deficiency in pregnancy and the postpartum. The clinical features of our cases and other reports are summarised in Table 1. The risk of developing hypercalcaemia during pregnancy and the postpartum appears greater in women with twin pregnancies, as occurred in our cases. The actual prevalence, management and long-term prognosis of patients with these CYP24A1 mutations is largely unknown, as experience is based on a few case reports in the literature. The most common morbidities described are nephrocalcinosis and nephrolithiasis due to hypercalciuria $(5,6)$. Other complications include pancreatitis (7), confusion and changes in mental state.

It is well documented that these patients can be asymptomatic and remain normocalcaemic. However, under circumstances that promote calcium absorption from the gut or kidneys and increased $1,25(\mathrm{OH})_{2} \mathrm{D}$ production, morbidity can result $(1,5,8)$. Intestinal absorption of calcium almost doubles in the third trimester of pregnancy in response to increased conversion of
$25(\mathrm{OH}) \mathrm{D}$ to its active metabolite $1,25(\mathrm{OH})_{2} \mathrm{D}$ by 1 -alpha hydroxylase expressed by the kidney and placenta. Like other case reports both of our patients had twin pregnancies $(4,6)$ where two placentas, each possessing the 1-alpha hydroxylase enzyme, would drive active Vitamin D production. In addition, consumption of Vitamin D and calcium supplements theoretically provides more substrate for the formation of active $1,25(\mathrm{OH})_{2} \mathrm{D}$.

Another interesting feature is the post-partum presentation or exacerbation of hypercalcaemia, also described in other cases $(4,7)$. After delivery there is a loss of maternofoetal calcium transfer. Intestinal calcium absorption and circulating $1,25(\mathrm{OH})_{2} \mathrm{D}$ normalise gradually in the post-partum period and while lactating. Bone resorption and renal reabsorption of calcium at this time increases in the mother through the action of PTHrP providing calcium for the breast milk during lactation (2). Rank ligand (RANKL)-mediated bone resorption is enhanced by a post-partum decrease in oestradiol concentrations and an increase in prolactin (2). RANKL is a member of the TNF superfamily found on the surface of osteoblasts, responsible for osteoclast differentiation and hence bone resorption. In the postpartum period, there seems to be an uncoupling of bone resorption and bone formation with a more pronounced increase in bone resorption markers, possibly through the action of RANKL (2). At least in vitro, $1,25(\mathrm{OH})_{2} \mathrm{D}$ is one of the most powerful inducers of RANKL and hence bone resorption (9). The paracrine effects of supraphysiological levels of $1,25(\mathrm{OH})_{2} \mathrm{D}$ on bone in CYP24A1 deficiency, associated with PTHrP and enhanced RANKL action, may be responsible for worsening hypercalcaemia in the postpartum period (6).

Management of these patients commences with avoidance of calcium and Vitamin D supplements and drugs that may promote hypercalcaemia by increasing renal reabsorption. The mainstays of treatment to lower serum calcium levels in pregnancy are i.v. isotonic saline, a loop diuretic and corticosteroids. In our cases these methods produced improvement but did not resolve the hypercalcaemia and caused adverse effects. Other potential therapies such as i.v. bisphosphonates, calcitonin, azoles and rifampicin can be considered outside of pregnancy and have been used with variable degrees of effectiveness $(4,8,10)$. Hypercalcaemia resolved after administration of denosumab to our patients in the postpartum period. It may be argued that calcium would have normalised given that other cases demonstrated resolution 4-8 weeks after delivery. However, we hypothesise that denosumab, 
being a monoclonal human antibody inhibiting RANKL, is likely to be more effective as it targets the main contributor to hypercalcaemia. Denosumab has been used effectively in hypercalcaemia of malignancy where ectopic secretion of osteoclast-activating factors, much like $1,25(\mathrm{OH})_{2} \mathrm{D}$, into the local or systemic circulation induces hypercalcaemia from enhanced bone resorption and may prove to be superior to bisphosphonates in malignancy and CYP24A1-induced hypercalcaemia, as occurred in our second case. Except during pregnancy because of potential safety issues, we suggest it be considered initial therapy for CYP24A1 deficiency-induced hypercalcaemia particularly for acute management of hypercalcaemia in the postpartum period and potentially for chronic management for patients with CYP24A1 deficiency to prevent hypercalcaemia, hypercalciuria and nephrolithiasis.

\section{Declaration of interest}

The authors declare that there is no conflict of interest that could be perceived as prejudicing the impartiality of this case report.

\section{Funding}

This research did not receive any specific grant from any funding agency in the public, commercial or not-for-profit sector

\section{Patients consent}

Both patients provided written consent for publication of case histories.

\section{Author contribution statement}

$\mathrm{N} \mathrm{A}$ (case 2) and C J E (case 1) provided medical care to the patients and wrote the first draft of the manuscript. $\mathrm{V}$ O'T (case 1) and T H (case 2) provided obstetric care for the patients. H C S provided medical care to case 1. R C B and C L performed the molecular genetic studies on the patients. All authors contributed to writing the manuscript.

\section{References}

1 Tebben PJ, Singh RJ \& Kumar R. Vitamin D-mediated hypercalcemia: mechanisms, diagnosis, and treatment. Endocrine Reviews 201637 521-547. (https://doi.org/10.1210/er.2016-1070)

2 Kovacs CS. Calcium and bone metabolism disorders during pregnancy and lactation. Endocrinology and Metabolism Clinics of North America 201140 795-826. (https://doi.org/10.1016/j.ecl.2011.08.002)

3 Schlingmann KP, Kaufmann M, Weber S, Irwin A, Goos C, John U, Misselwitz J, Klaus G, Kuwertz-Bröking E, Fehrenbach H, et al. Mutations in CYP24A1 and idiopathic infantile hypercalcemia. New England Journal of Medicine 2011365 410-421. (https://doi. org/10.1056/NEJMoa1103864)

4 Dinour D, Davidovits M, Aviner S, Ganon L, Michael L, ModanMoses D, Vered I, Bibi H, Frishberg Y \& Holtzman EJ. Maternal and infantile hypercalcemia caused by vitamin-D-hydroxylase mutations and vitamin D intake. Pediatric Nephrology 201530 145-152. (https:// doi.org/10.1007/s00467-014-2889-1)

5 Jacobs TP, Kaufman M, Jones G, Kumar R, Schlingmann KP, Shapses S \& Bilezikian JP. A lifetime of hypercalcemia and hypercalciuria, finally explained. Journal of Clinical Endocrinology and Metabolism 201499 708-712. (https://doi.org/10.1210/jc.2013-3802)

6 Shah AD, Hsiao EC, O’Donnell B, Salmeen K, Nussbaum R, Krebs M, Baumgartner-Parzer S, Kaufmann M, Jones G, Bikle DD, et al. Maternal hypercalcemia due to failure of 1,25-dihydroxyvitamin-D3 catabolism in a patient with CYP24A1 mutations. Journal of Clinical Endocrinology and Metabolism 2015100 2832-2836. (https://doi. org/10.1210/jc.2015-1973)

7 Woods GN, Saitman A, Gao H, Clarke NJ, Fitzgerald RL \& Chi NW. A young woman with recurrent gestational hypercalcemia and acute pancreatitis due to CYP24A1 deficiency. Journal of Bone and Mineral Research 201631 1841-1844. (https://doi.org/10.1002/jbmr.2859)

8 Sayers J, Hynes AM, Srivastava S, Dowen F, Quinton R, Datta HK \& Sayer JA. Successful treatment of hypercalcaemia associated with a CYP24A1 mutation with fluconazole. Clinical Kidney Journal 20158 453-455. (https://doi.org/10.1093/ckj/sfv028)

9 Takahashi N, Udagawa N \& Suda T. Vitamin D endocrine system and osteoclasts. BoneKEy Reports 20143 495. (https://doi.org/10.1038/ bonekey.2013.229)

10 Tebben PJ, Milliner DS, Horst RL, Harris PC, Singh RJ, Wu Y, Foreman JW, Chelminski PR \& Kumar R. Hypercalcemia, hypercalciuria, and elevated calcitriol concentrations with autosomal dominant transmission due to CYP24A1 mutations: effects of ketoconazole therapy. Journal of Clinical Endocrinology and Metabolism 201297 E423-E427. (https://doi.org/10.1210/jc.2011-1935)

11 Hedberg F, Pilo C, Wikner J, Torring O \& Calissendorff J. Three sisters with heterozygous gene variants of CYP24A1: new-onset hypertension, and neonatal hypoglycaemia. Journal of the Endocrine Society 20193 387-396. (https://doi.org/10.1210/js.2018-00337) 